\title{
Consumo incidental de plástico y otros materiales antropogénicos por parte de Coragyps atratus (Bechstein, 1793) en un vertedero de basura de Ecuador
}

\author{
Incidental consumption of plastic and other anthropogenic materials by Coragyps atratus \\ (Bechstein, 1793) in a garbage dump in Ecuador
}

\author{
Enrique Richard* 1 \\ https://orcid.org/0000-0002-0061-7807 \\ chelonos@gmail.com \\ Denise Ilcen Contreras Zapata ${ }^{2}$ \\ https://orcid.org/0000-0001-7912-7095 \\ dennycz@gmail.com \\ Fabio Angeoletto ${ }^{3}$ \\ https://orcid.org/0000-0002-3084-3928 \\ fabio_angeoletto@yahoo.es

\section{*Corresponding author}

1 Universidad San Gregorio de Portoviejo (Ecuador). Posgrado de la Universidad Andina Simón Bolívar (Bolivia) \& Universidad Mayor de San Andrés (Bolivia).

2 Universidad San Gregorio de Portoviejo (Ecuador). Programa de Doctorado en Pedagogía, Universidad Andina Simón Bolívar (Bolivia).

3 Universidad Federal de Mato Grosso, Mato Grosso (Brasil).

\section{Citación}

Richard E, Contreras Zapata DI, Angeoletto F. 2021. Consumo incidental de plástico y otros materiales antropogénicos por parte de Coragyps atratus (Bechstein, 1793) en un vertedero de basura de Ecuador. Revista peruana de biología 28(4): e21627 (Noviembre 2021). doi: http://dx.doi.org/10.15381/ rpb.v28i4.21627

$\begin{array}{ll}\text { Presentado: } & 13 / 07 / 2020 \\ \text { Aceptado: } & 27 / 02 / 2021 \\ \text { Publicado online: } & 26 / 11 / 2021 \\ \text { Editor: } & \text { Cesar Arana }\end{array}$

\section{Resumen}

En este estudio se analiza y discute la ingesta de plástico y otros materiales antropogénicos por parte de Coragyps atratus en un vertedero de residuos suburbano de Calceta, Provincia de Manabí, Ecuador. De un total de 112 egagrópilas analizadas, el $100 \%$ contenía materiales antropogénicos siendo los más conspicuos, diferentes tipos de plásticos y microplásticos, además de metales, vidrio, suelo y otros. Se discute y contrasta con la bibliografía la importancia relativa de los materiales antropogénicos encontrados, así como su potencial impacto en la especie y para el ser humano.

\section{Abstract}

This study analyzes and discusses the ingestion of plastic and other anthropogenic materials by Coragyps atratus in a suburban waste dump in Calceta, Manabí Province, Ecuador. Of a total of 112 pellets analyzed, 100\% contained anthropogenic materials, the most conspicuous being different types of plastics and microplastics, as well as metals, glass, soil, and others. The relative importance of the anthropogenic materials found is discussed and analyzed, same as their potential impact on the species and humanity.

Palabras claves:

Botaderos de basura; residuo orgánico; rellenos sanitarios; antropoceno; plastisfera; bioacumulación; Cathartidae; egagrópilas; suelo; conservación; contaminación plástica; carroñeros; ecología urbana.

\section{Keywords:}

Rubbish dumps; Organic waste; landfills; anthropocene; plastisphere; bioaccumulation; Cathartidae; pellets; soil; conservation; plastic pollution; scavengers; urban ecology.

\section{Introducción}

La humanidad está produciendo en forma exponencial grandes cantidades de residuos que se desechan como basura (Ballejo et al. 2020, Stothra Bhashyam et al. 2021, Noreen \& Sultan 2021). Una porción de ésta contiene material orgánico originado de alimentos domésticos de los seres humanos (Parfitt et al. 2010); pero, también existe una gran proporción de elementos inorgánicos desechados como metal, vidrio, cerámica y loza; además de orgánicos, sintéticos como pedazos de telas, medicamentos, gomas, plásticos duros y blandos (Barnes et al. 2009). Los plásticos ocupan a nivel global aproximadamente el 50\% de lo que llega a los vertederos de residuos y la tendencia sugiere un aumento exponencial de este contenido (Geyer et al. 2017, ONU 2018, Fernández 2020, Stothra Bhashyam et al. 2021). Su amplia distribución y disponibilidad en el ambiente ha originado que, como producto nuevo del antropoceno, actualmente se hable de una "plastisfera" (Zettler et al. 2013, Katyal et al. 2020). 
Se han realizado varios estudios sobre la ecología trófica de aves carroñeras (Houston 1988, Iñigo 1987, Chamberlain et al. 2005, Kelly et al. 2007, Houston et al. 2007, Lambertucci et al. 2009, Margalida et al. 2009, Ballejo \& De Santis 2013, Noreen \& Sultan 2021), y se conoce que varias de estas aves utilizan comúnmente los vertederos de residuos como fuente de recursos tróficos (subsidios) (Moleón et al. 2014, Plaza \& Lambertucci 2017, Noreen \& Sultan 2021). Aunque la ingesta de materiales antropogénicos (MA) ha sido relativamente bien estudiada en aves acuáticas (Wilcox et al. 2015), en aves carroñeras es bastante menos conocida (Carlin et al. 2020). Coragyps atratus (Bechstein, 1793) es considerada como carroñera obligada (Ballejo \& De Santis 2013, Moleón et al. 2014), pero también oportunista (Ballejo \& De Santis 2013, Ballejo et al. 2020) y con evidentes características urbanófilas (Witte et al. 1985), sinantrópicas (Johnston 2001) o explotadoras del ecosistema urbano (McKinney 2002) en función a su afinidad con el ser humano y ecosistemas urbanos y rurales (e.g. Iñigo 1987, Kelly et al. 2007, Plaza \& Lambertucci 2017, Ballejo et al. 2020). Consecuentemente, se ha observado que C. atratus tiene un amplio espectro trófico, que suele incluir materiales no biológicos generados por las actividades humanas (Iñigo 1987, Kelly et al. 2007, Ballejo \& De Santis 2013, Ballejo et al. 2020, Noreen \& Sultan 2021).

De acuerdo con Plaza y Lambertucci (2017) los vertederos de residuos representan fuentes de alimentos o subsidios tróficos con atributos tanto positivos como negativos. Los vertederos de residuos están distribuidos en todo el mundo, son abundantes, predecibles espacial y temporalmente, renovados diariamente y representan una fuente potencial de alimento para muchas especies, ya que en ellos se encuentran, en diferentes proporciones, partes de carne, pescado, pollo, fruta fresca, harinas y huevos (Parfitt et al. 2010), y que pueden ser explotados por diferentes especies y utilizarse como parte de sus requerimientos calóricos (Oro et al. 2013, Angeoletto et al. 2022). Por otra parte, junto a estos subsidios tróficos antropogénicos también se encuentran vidrios, metales, alambres, plásticos, pinturas, diferentes tóxicos y patógenos peligrosos, que pueden afectar la salud y abundancia de estas especies (Flores-Tena et al. 2007, Houston et al. 2007, Matejczyk et al. 2011, Wiemeyer et al. 2021). Por consiguiente y conforme lo indican Plaza y Lambertucci (2017), aprovechar estos subsidios alimentarios podría producir impactos contrastantes en las poblaciones de vertebrados que habitan los vertederos y que deberían ser estudiados en detalle.

El rol de aves carroñeras también resulta relevante por el consumo de los animales que mueren por enfermedad, disminuyendo los focos de infección y evitando la propagación de estas (Moleón et al. 2014, Plaza \& Lambertucci 2018, Plaza et al., 2019, 2020, Noreen \& Sultan 2021). Por ello, la remoción de desechos animales por parte de los buitres antes de su putrefacción es considerada uno de los más importantes servicios ambientales (Moleón et al. 2014, Noreen \& Sultan 2021). Sin embargo, algunos subsidios alimentarios provenientes de vertederos antropógenos pueden tener patógenos que sobrevivan a los ácidos gástricos del sistema digestivo y afectar la salud de estas aves (Sazima 2007, Plaza et al. 2019, 2020).

Aunque los hábitos alimenticios de C. atratus han sido estudiados tanto en contextos naturales, como urbanos, suburbanos y específicos para vertederos de basura (Paterson 1984, Yahner et al. 1986, 1990, Coleman \& Fraser 1987, Iñigo 1987, Thomaides et al. 1989, Hiraldo et al. 1991, Kelly et al. 2007, Ballejo \& De Santis 2013, Carlin et al. 2020, Ballejo et al. 2020, Noreen \& Sultan 2021), en general dichos estudios se han limitado a brindar información porcentuales de la ingesta total, sin discriminación de los diferentes tipos de plástico y otros MA. Dichos plásticos, por su estructura y composición varían en su capacidad de captación, adsorción, absorción de compuestos orgánicos persistentes (COP's) y otras sustancias tóxicas (Tu et al. 2020, Stothra Bhashyam et al. 2021).

En este trabajo, documentamos por primera vez el consumo de materiales antropogénicos, en particular de plásticos por parte de C. atratus en un vertedero de residuos suburbano de Calceta, Provincia de Manabí (Ecuador). Analizamos y discutimos en el contexto de estudios previos este reporte y los potenciales riesgos a la salud que conlleva el consumo de plásticos y la exposición a algunos de estos MA para la especie.

\section{Material y métodos}

El estudio se realizó en el vertedero de residuos de la municipalidad de Calceta que se encuentra en la vía Tosagua-Calceta, en el sector el Mirador, Provincia de Manabí, Cantón Bolívar, (050’57.42” S, 80¹3'28.19” W, Fig. 1). El sitio es propiedad del municipio, tiene un área total 9.34 ha (Fig. 1 y Fig. 2) y fue visitado durante cinco días cada semana, por un período de dos meses (15 de enero de 2019 al 15 de marzo de 2019).

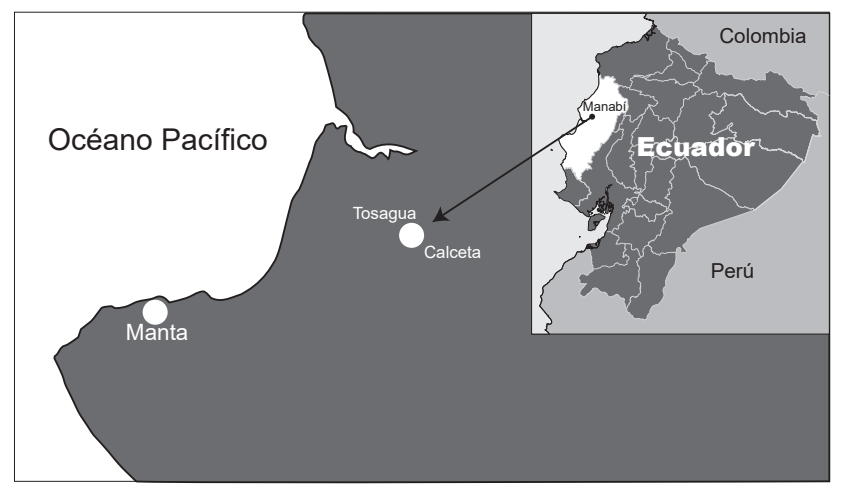

Figura 1. Ubicación del vertedero de residuos municipal de Calceta que se encuentra en la vía Tosagua-Calceta, en el sector el Mirador Provincia de Manabí, Cantón Bolívar.

En este vertedero se congrega una gran cantidad de individuos de $C$. atratus que pueden observarse tanto en vuelo como posados en el suelo y asociados a otras aves como garcitas bueyeras (Bubulcus ibis), garrapateros (Crothophaga ani) y en menor medida palomas domésticas (Columba livia). 
Para determinar la presencia de MA en la dieta de $C$. atratus se colectaron y analizaron sus egagrópilas. Esta es una de las técnicas más utilizadas en aves carroñeras por su relativamente fácil acceso y obtención, permitiendo obtener datos sin afectar a las aves (Ballejo \& De Santis 2013). El procedimiento consistió en identificar las perchas donde se posaban los individuos de la especie (Fig. 3); estableciéndose 14 perchas a observar durante el periodo de estudio (Fig. 4). Las bases de los posaderos fueron limpiadas con el fin de eliminar las egagrópilas antiguas y recoger sólo las correspondientes al periodo de estudio. Luego se procedió a tomar las egagrópilas tan pronto eran observadas al pie de cada percha. La documentación fotográfica y en video del trabajo de campo se hizo con cámaras Nikon S9700 (C) con GPS incorporado (Frecuencia de recepción 1575,42 MHz, sistema geodésico WGS 84) y Nikon D7200 (C) con lente Nikkor(C) 55-300 mm.

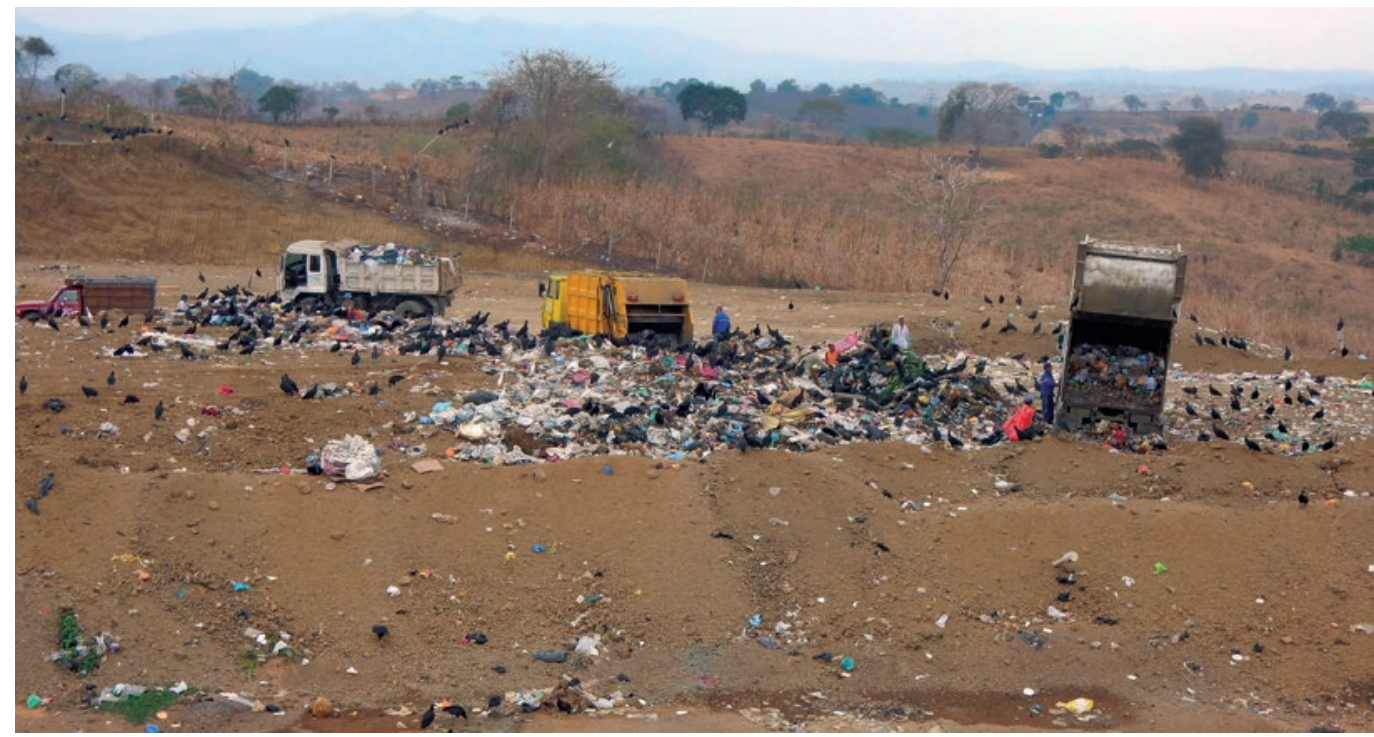

Figura 2. Vertedero de residuos de la municipalidad de Calceta, vía Tosagua-Calceta, sector el Mirador Provincia de Manabí, Cantón Bolívar, Ecuador (050' 57.42" S, 80¹3' 28.19" W). Área de estudio. Foto E. Richard.

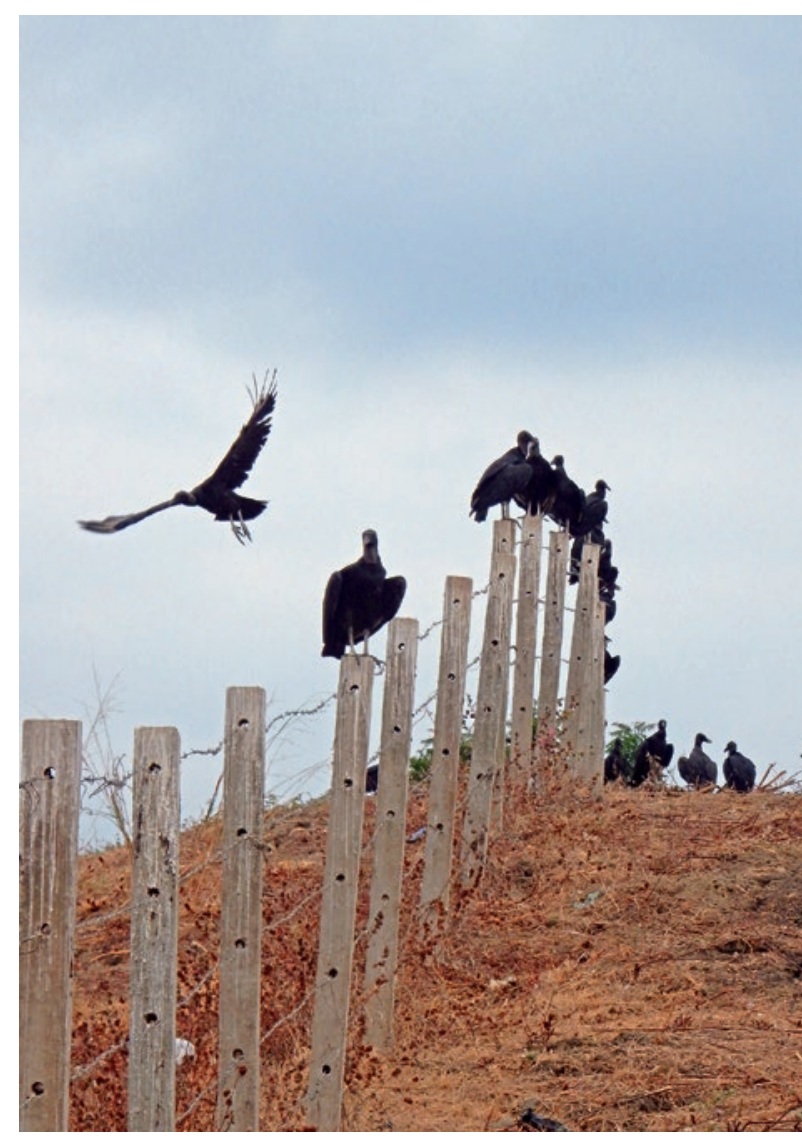

Figura 3. Perchas identificadas con presencia permanente de individuos de Coragyps atratus en el vertedero. Foto: E. Richard.

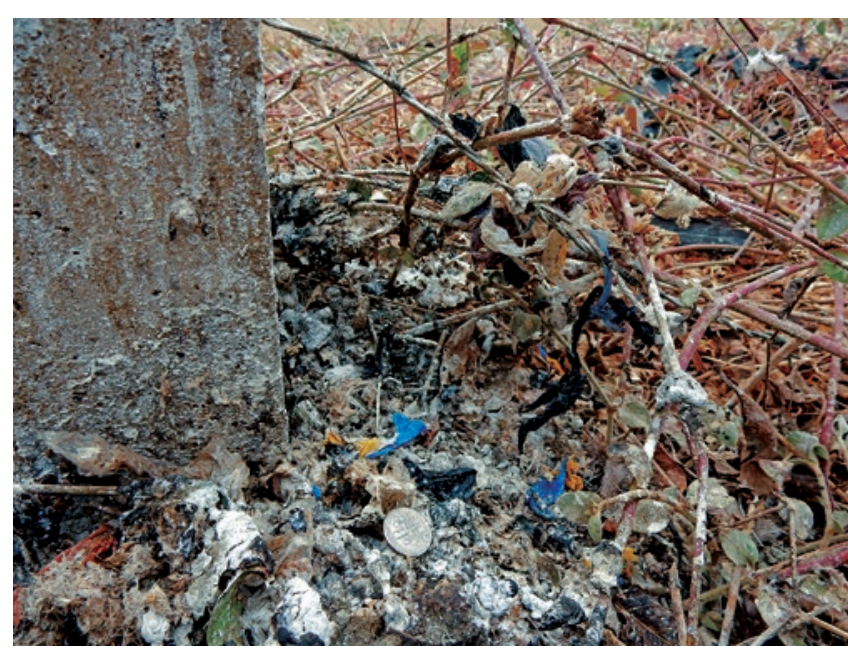

Figura 4. Egagrópilas acumuladas sobre una percha de Coragyps atratus. Nótese la gran cantidad de plástico contenido y emergente de ellas. Foto: E. Richard.

De esta forma, se tomó un total de 298 egagrópilas de las cuales se seleccionaron 112 egagrópilas "discretas" para su estudio. Las restantes se descartaron por no tener la condición "discreta"; es decir se trataba de egagrópilas fusionadas en distinto grado con otras y por tanto no aptas a los fines estadísticos. Las egagrópilas fueron procesadas y analizadas en el laboratorio de la Carrera de Medicina de la Universidad San Gregorio de Portoviejo (Ecuador). Se colocaron sobre un cedazo de aluminio 
(Malla mosquitera) de $30 \times 30 \mathrm{~cm}$, luego fueron secadas desde abajo con aire caliente a $45^{\circ} \mathrm{C}$ durante 4 horas con un secador de pelo y guardadas en cajas plásticas cerradas herméticamente con sílica gel. Durante las 72 horas posteriores, cada egagrópila fue colocada para su estudio en una bandeja plástica y diseccionada con pinzas de punta y planas. Para la identificación de MA se utilizó una lupa binocular con iluminación led (5x a 25x de aumento). El protocolo consistió en inspeccionar primero la compactación de la muestra, detectando la presencia de MA y luego, lentamente, se procedía a desarmar la egagrópila de afuera hacia adentro. En el caso de las egagrópilas con gran cantidad de lana, muy compactas (similares al fieltro), se utilizó tijeras quirúrgicas.
Siguiendo a Coleman y Fraser (1987) que criticaron los cálculos e índices de volumen porcentual en egagrópilas debido a que no todos los alimentos son igualmente digeribles; en este trabajo sólo se consideró la presencia de los MA y se clasificaron en categorías discretas (S =18). Para cada categoría se indica el número de egagrópilas en las que se halló componentes de dichas categorías $(=n)$; así como la frecuencia observada $\left(n_{i}\right)$ expresada en porcentual relativo de componentes ó ítems de cada categoría hallados en las muestras (nx100/112 egagrópilas). De igual forma se calculó la abundancia relativa expresada como el coeficiente de la frecuencia observada (ni) y el número total de ítems de todas las categorías $\left(\mathrm{N}=\sum \mathrm{ni}=351\right)$ (Tabla 1$)$.

Tabla 1: Materiales de origen antropogénicos y suelo hallado en las egagrópilas del sitio de estudios y analizadas acorde a las categorías discretas

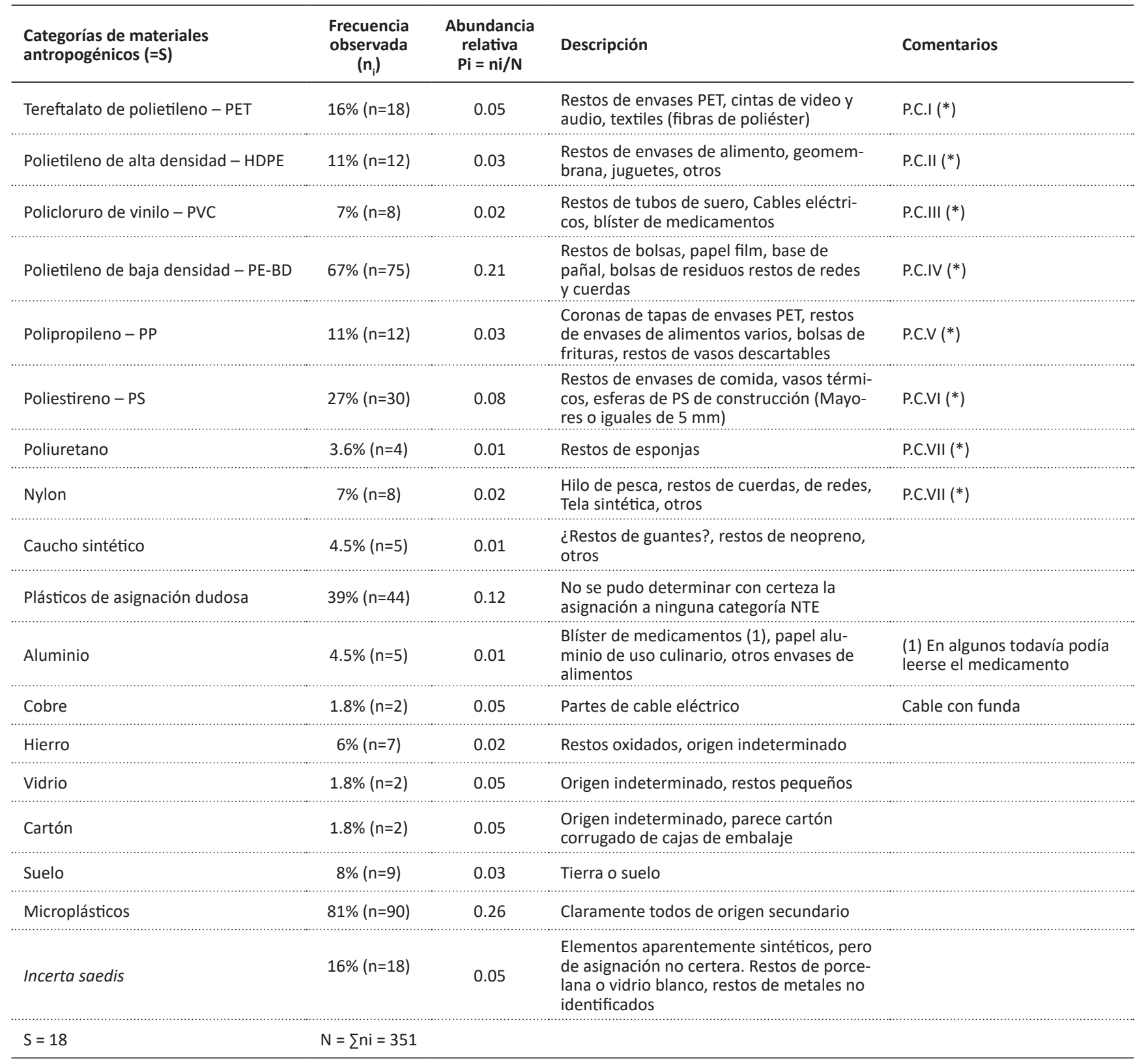

Total de categorías o ítem (=S) de elementos antropogénicos registrados: 18

$\left({ }^{*}\right)$ P.C. = Plásticos de categoría I a VII acorde a la Norma Técnica Ecuatoriana (2012)

La egagrópila con menor cantidad de ítems de origen antropogénico tuvo sólo cuatro, en tanto la de mayor diversidad tuvo 11 
Para darles identidad a las categorías de plásticos, aquellos identificados en forma certera fueron catalogados acorde a la Norma Técnica Ecuatoriana NTE (INEN 2012) que adopta la clasificación internacional de la Sociedad de la Industria de Plásticos (SPI). Se incluyó en la categoría "plásticos de asignación dudosa" a los fragmentos de plástico cuya asignación a alguna categoría NTE no fuera certera. La categoría "microplásticos" incluye aquellos fragmentos (no incluidos en categorías previas) con un tamaño inferior a los 5 mm (Courtney et al. 2009) e Incertae saedis para materiales de asignación incierta.

En el caso de los microplásticos, debido a las limitantes de la lupa binocular (resolución relativamente reducida y difracción de los lentes) utilizada, las partículas muy pequeñas (menores de $1 \mathrm{~mm}$ ) resultaban indistinguibles de granos de tierra o arena por lo cual existía el sesgo de asignar algunas de tales partículas a la categoría "microplásticos". Por tanto, en la categoría "microplásticos" sólo incluimos las partículas comprendidas entre 1 y $5 \mathrm{~mm}$ que certeramente correspondían a material plástico. Los restos o microfragmentos de fibras, ante la imposibilidad de identificar su potencial origen sintético con la lupa mencionada, no fueron consideradas en este trabajo. Adicionalmente se incluyó la categoría "suelo" para materiales identificados con el suelo local y como parte de los componentes analizados.

\section{Resultados y discusión}

Se halló MA en el 100 \% de las egagrópilas (n=112), aunque con diferentes frecuencias y proporciones (Tabla 1, Figura 5). Esto documenta por vez primera la incidencia de MA en el espectro trófico de C. atratus para Ecuador y en relación con un entorno antropogénico suburbano: el vertedero de residuos de Calceta, Manabí. En el caso del plástico se hallaron las siete categorías reconocidas de plástico acorde a la Norma Técnica Ecuatoriana (INEN 2012) y parámetros internacionales. Complementariamente, se encontró otros MA tanto sintéticos, como orgánicos e inorgánicos incorporados a la lista (Tabla 1).
Dado que $C$. atratus posee evidentes características de explotador urbano (McKinney 2002), urbanofila (Witte et al. 1985) o sinantrópica (Johnston 2001) al extremo de haber adquirido el hábito de utilizar los vertederos de residuos como fuente de alimento (Ballejo et al. 2020); no debería sorprender encontrar MA en sus egagrópilas. Sin embargo, un análisis de la literatura indica que estos MA suelen aparecer en proporciones relativamente reducidas en relación con la porción orgánica de alimento habitual y no se cuenta con información de la abundancia de MA respecto a otros materiales ingeridos (Iñigo 1987, Kelly et al. 2007, Ballejo \& De Santis 2013, Ballejo et al. 2020, Carlin et al. 2020, Noreen \& Sultan 2021; Tabla 2).

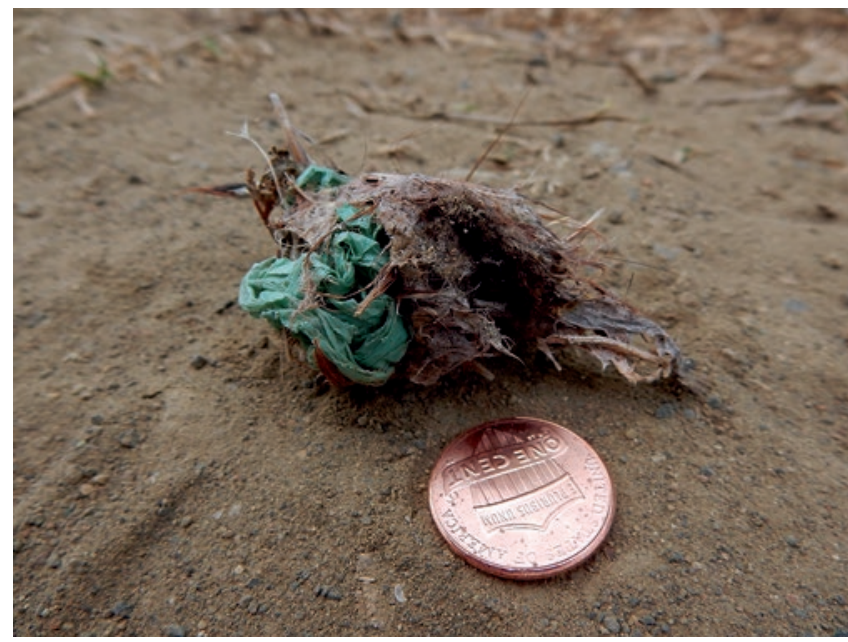

Figura 5. Egagrópila de Coragyps atratus, nótese que gran parte de su volumen está formado por plástico. Asimismo, nótese la presencia de puntas duras emergentes y material queratinoso. Foto: E. Richard.

Tampoco se halló en la literatura análisis que reporten una diversidad tan amplia de MA como la que aquí se presenta (Tabla 1 y 2) (Iñigo 1987, Kelly et al. 2007, Ballejo \& De Santis 2013, Ballejo et al. 2020, Noreen \& Sultan 2021). Para Ecuador concretamente, no se disponen de registros previos de la presencia de MA en egagrópilas de C. atratus.

Tabla 2: Categorías de MA (CMA) analizadas y porcentual relativo de plásticos respecto a la porción orgánica en egagrópilas para Coragyps atratus, acorde a diferentes autores y en diferentes contextos.

\begin{tabular}{|c|c|c|c|}
\hline Autores & Área de estudio & $\mathrm{CMA} / \%(*)$ & \% plástico \\
\hline Iñigo (1987) & Tuxtlas (México), área rural y urbana & $10 / 39.1 \%$ & $70 \%$ \\
\hline Kelly et al. (2007) & Savannah River, South Carolina, USA área rural & $3 / 12.5 \%$ & $8.3 \%$ \\
\hline Ballejo y De Santis (2013) & $\begin{array}{l}\text { Dina Huapi (Rio Negro), área urbana y Estancia } \\
\text { Chacabuco (Neuquén) área rural Argentina }\end{array}$ & $\begin{array}{l}11 / 28 \% \text { área urbana } \\
1 / 3.4 \% \text { área rural }\end{array}$ & $\begin{array}{l}15 \% \text { área urbana } \\
0 \% \text { área rural }\end{array}$ \\
\hline Ballejo et al. (2020) & Neuquén y Rio Negro, Argentina & $6 / 100 \%$ & $67 \%$ \\
\hline Carlin et al. (2020) & Florida, USA & $2 / 100 \%$ & $100 \%\left({ }^{* *}\right)$ \\
\hline Noreen y Sultan (2021) & $\begin{array}{l}\text { Varios países, revisión que incluyen varias especies } \\
\text { de Cathartidae }\end{array}$ & No se consignan & $34-83 \%$ \\
\hline Este trabajo & Calceta, Ecuador, área rural & $18 / 61 \%$ & $100 \%$ \\
\hline
\end{tabular}

$\left({ }^{*}\right)$ La columna de \% de plástico indica el porcentual de materiales plásticos dentro de las categorías CMA en las egagrópilas analizadas.

$(* *)$ Referido al hallazgo en dos muestras de contenido gastrointestinal. Estos autores no analizaron egagrópilas. 
Las categorías discretas aquí consideradas muestran una riqueza de $n=18$ ítems de MA para las 112 egagrópilas colectadas. El 100\% de ellas, contenía alguna o varias de las categorías mencionadas. En este sentido, Iñigo (1987) encontró, para el Valle de Tuxtlas (México), en un área rural y urbana, que solo el 39.1\% de las egagrópilas presentaban MA y de ellos, el 70\% era plástico. Otros autores (Kelly et al. 2007, Ballejo \& De Santis 2013, Ballejo et al. 2020), reportan porcentajes relativamente menores (Tabla 2).

Existiría entonces una correlación entre la presencia de plásticos y otros MA y la distancia a los lugares de alimentación de la especie, como lo observaron Ballejo et al. (2020). De hecho, Plaza y Lambertucci (2017) indican que los vertederos son un factor importante para el movimiento de estos animales. Por tal motivo, la selección de sitios de percha cercanos al vertedero sería importante para $C$. atratus y estaría relacionado a la reducción del costo energético de los desplazamientos (Novaes \& Cintra 2013). Esta situación se pudo constatar en el presente estudio, donde la totalidad de sitios de percha de la especie estaban localizados en el perímetro del vertedero (Fig. 3)

Houston et al. (2007) proponen tres hipótesis no mutuamente excluyentes entre sí para el consumo de MA por parte de cóndores (Cathartidae) y buitres del viejo mundo (Accipitridae). Estas son: 1) En la basura encuentran objetos confundidos con hueso o fragmentos de estos, 2) Objetos extraños necesarios para la formación de la egagrópila, 3) Objetos confundidos con nuevas fuentes de energía. Estos autores argumentan que, los buitres del viejo mundo y cóndores, al tener un cuello y esófago más largo que otros carroñeros (por ejemplo C. atratus y $C$. aura), encuentran más dificultoso evacuar sus egagrópilas. Por otro lado, al alimentarse especialmente de vísceras y carne, no ingerirían mucho material duro o fibroso para formar una egagrópila. Esto los motivaría a buscar con intención material extraño para formar la egagrópila y estimular el peristaltismo que permita evacuarla. Dado que la "basura" se encuentra ampliamente disponible para aquellas especies; sería entonces el material elegi- do para formar la egagrópila y estimular su evacuación (Houston et al. 2007).

En contraposición, C. atratus y C. aura ingieren comúnmente piel con pelos, plumas, etc.; es decir mucho material queratinoso no digerible que permite la formación de la egagrópila (Houston et al. 2007). Al tener cuellos más cortos que los cóndores y buitres del viejo mundo, la evacuación sería más fácil también. Por tanto, C. atratus y $C$. aura no tendrían la necesidad de buscar y consumir "basura". En este sentido, las egagrópilas aquí estudiadas; por un lado, indican que $C$. atratus consume material queratinoso (por ejemplo plumas, Fig. 5) indigerible; aún en un vertedero de residuos y, junto a ellos, una cantidad significativa de MA (Tabla 1 ).

De hecho, materiales queratinosos, incluyendo pelos en grandes cantidades y plumas con sus cálamos en punta, fueron encontrados en el 87\% de las egagrópilas y en cantidades perceptivamente representativas (30 a $40 \%$ del volumen de la egagrópila) (Fig. 5). Por lo tanto, la presencia de MA, al menos para $C$. atratus, no podría justificarse, ni por la ausencia de material queratinoso, ni por tener cuellos y esófagos "cortos" como lo señalan los supuestos de Houston et al. (2021). Consecuentemente, en este estudio, nos inclinamos por atribuir la presencia de MA (Houston et al. 2007) en las egagrópilas a un consumo incidental de la misma.

Los vertederos de residuos serían la principal fuente de origen de los MA que aparecen en las egagrópilas, debido a la alta disponibilidad de estos y a que normalmente se encuentran cubriendo o asociados en distinto grado a los residuos orgánicos que la especie busca como alimento. Consecuentemente, resulta lógico que, al intentar acceder a estos residuos, incidentalmente ingieran porciones de los plásticos asociados o que los cubren. Es probable, como señala Sazima (2007), que los gallinazos relacionen o asocien los plásticos con sus alimentos habituales (carroña) como parte de un comportamiento adquirido. Sobre todo, los de uso más frecuente como las bolsas (categoría IV) (Fig. 6).

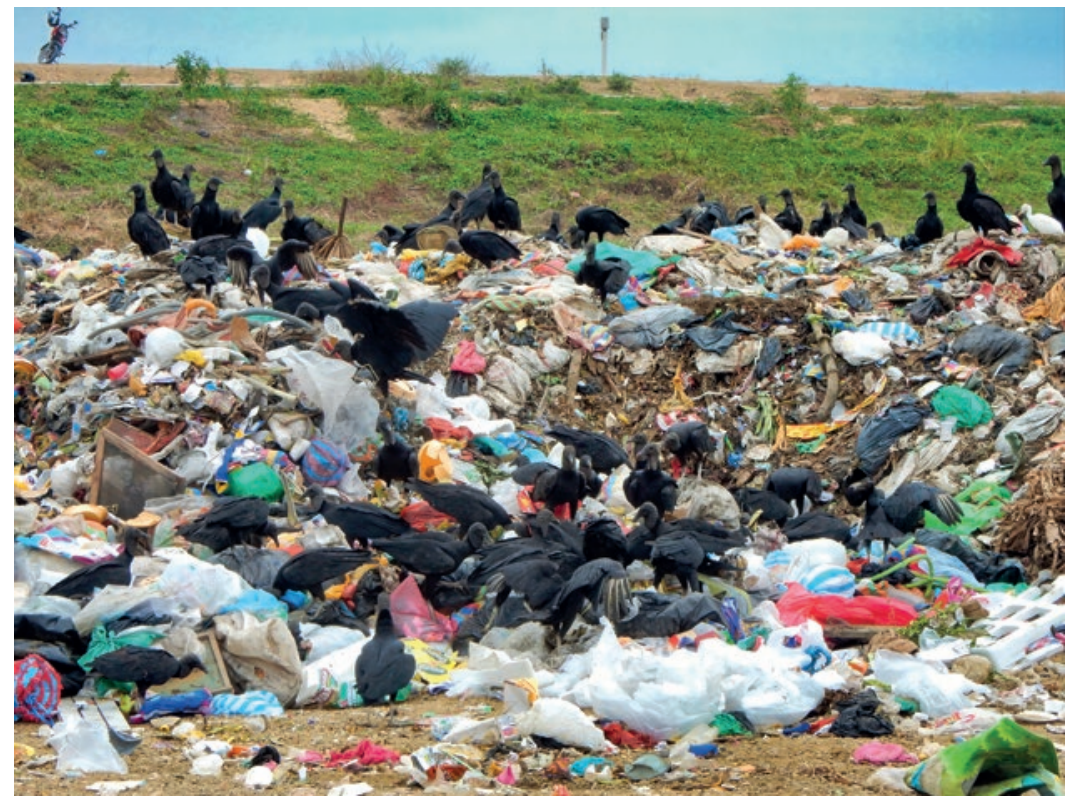

Figura 6. Los plásticos de la categoría IV son perceptiblemente los más abundantes en el vertedero y mayormente envuelven los residuos orgánicos que busca Coragyps atratus. Foto: E. Richard. 
Los plásticos de categoría IV representados en 75 egagrópilas (67\%; pi=ni/N=0.21, Tabla 1) serían ingeridos incidentalmente, pero consecuentes con una conducta adquirida de asociar las bolsas plásticas con comida (Sazima 2007). Sobre el particular, Sazima (2007) observó que $C$. atratus es atraído por las bolsas de residuos (plásticos categoría IV), contengan o no, alimentos. Pero, en todos los casos, rompen las bolsas y otro tipo de envolturas para acceder a sus contenidos (Sazima 2007).

Un dato interesante es que la especie ingiere no sólo carroña y restos orgánicos, sino también fruta fresca (Sazima 2007); lo que cuestionaría hasta cierto punto su estatus de carroñero obligado (Ballejo \& De Santis 2013, Moleón et al. 2014) y reforzaría el estatus de especie oportunista (Ballejo \& De Santis 2013, Ballejo et al. 2020). Los vertederos son una fuente de alimentos diversos y abundantes para estas aves, lo que explicaría su aumento poblacional en la región (Ballejo et al. 2020, Noreen \& Sultan 2021) y la congregación de grandes concentraciones de aves en un área relativamente pequeña como un vertedero de residuos (Novaes \& Cintra 2013, Noreen \& Sultan 2021, este estudio, Figs. 2 y 6). Noreen y Sultan (2021), indican que, si bien los vertederos representan una fuente importante de recursos tróficos de fácil acceso, la calidad de estos alimentos probablemente no sea la adecuada. En efecto, estos autores señalan que los alimentos hallados en los vertederos son de pobre calidad, pero altos en grasa y valor calórico en relación con los alimentos originales (carroña). Pero, la adaptación a consumir esta nueva oferta de alimentos hace a estas especies exitosas; como lo demuestra, entre otros, el crecimiento demográfico de la especie en su área de distribución (Ballejo et al. 2020, Noreen \& Sultan 2021).

Como contrapartida, en algunos vertederos alrededor del mundo, el consumo de alimentos junto a plásticos asociados a compuestos tóxicos, como pesticidas, diclofenaco y otros, ha motivado la reducción de poblaciones de buitres (Accipitridae especialmente), incluso a niveles críticos (Swan et al. 2006, Moleón et al. 2014, Margalida et al. 2014, Noreen \& Sultan 2021). El diclofenaco, antiinflamatorio no esteroide, es un medicamento utilizado en medicina tanto humana como veterinaria y en países en vías de desarrollo, incluyendo a Ecuador, es de venta libre. En el caso del ganado y los seres humanos es ampliamente usado; pero está demostrado que, en pequeñas cantidades, es letal para algunos buitres del género Gyps y otras especies de Accipitridae (Oaks \& Meteyer 2012, Margalida et al. 2014). Por esta razón, el diclofenaco ha sido señalado como responsable de la declinación de varias especies de buitres alrededor del mundo (Swan 2006, Ogada et al. 2012, Margalida et al. 2014, Plaza \& Lambertucci 2017).

Otros estudios indicarían que en Cathartidae, concretamente en Cathartes aura, el diclofenaco no tendría efectos tan letales (Oaks \& Meteyer 2012). El problema del diclofenaco, es importante destacarlo, debido a que en el vertedero de Calceta se encontró una gran cantidad de blisters de diferentes medicamentos (Aprox. en el 7\% de las egagrópilas, $\mathrm{pi}=\mathrm{ni} / \mathrm{N}=0.02$, Tabla 1) y otros resi- duos farmacéuticos (frascos, jeringas, ampollas). Asimismo, tanto el plástico de los blisters, como la cubierta de aluminio, se constató en algunas egagrópilas analizadas (Tabla 1, plásticos categoría III). Sin embargo, no fue posible identificar a que medicamentos pertenecían. Pero, teniendo en cuenta la frecuencia de uso del diclofenaco, tanto a nivel veterinario, como humano en Ecuador, es probable que el mismo se encuentre disponible para su consumo incidental en el vertedero; ya sea como residuo de medicamento, partidas vencidas o como contaminante de restos de alimentos (carne vacuna, por ejemplo). Un interesante problema para abordar en futuras investigaciones.

Los nuevos hábitos de alimentación adquiridos en torno a estos subsidios de alimentos de origen antropogénico (Gangoso et al. 2012, Moleón et al. 2014, Plaza et al. 2019, Noreen \& Sultan 2021) ha producido diferentes impactos. Si bien estas aves consumen material orgánico de los vertederos, disminuyendo los potenciales focos de proliferación de bacterias patógenas (Plaza \& Lambertucci 2018, Plaza et al. 2019); incidentalmente también, lo harían con material sintético o antropogénico asociado con los mismos (Plástico, vidrio, metales). Esto, en muchas ocasiones, deriva en problemas nutricionales, infecciones, alteraciones metabólicas, obstrucciones de intestino, entre otros (Mee et al. 2007, Rideout et al. 2012, Plaza \& Lambertucci 2018, Plaza et al. 2019, Tauler-Ametller et al. 2019, Ballejo et al. 2020, Noreen \& Sultan 2021).

Parte de los plásticos y otros MA ingeridos, junto a los materiales orgánicos de los vertederos, son posteriormente regurgitados en sus egagrópilas (Augé 2017, Houston et al. 2007, Iñigo 1987, Sazima 2007, Ballejo et al. 2020, este trabajo) (Figs. 4 y 5). Pero, dado que dichas egagrópilas no son regurgitadas inmediatamente, y los buitres recorren cotidianamente grandes distancias, potencialmente se convierten en vectores de dispersión de estos desechos (especialmente plásticos) hacia áreas prístinas remotas, generando "islas de plástico" (Ballejo et al. 2020). De hecho, simplemente observando las perchas donde se posan los C. atratus en el vertedero, se puede apreciar y constatar el mecanismo propuesto por Ballejo et al. (2020). A los pies de estas, se acumula el plástico regurgitado rápidamente (Fig. 3 y 4) formando una pequeña isla de plástico. Luego, esta crece como núcleo de acreción en altura, profundidad y lateralmente, en todas las direcciones. Tiempo después, se termina uniendo al núcleo de acreción vecino conformando una isla de mayor tamaño, resultante de la fusión de los citados núcleos.

Los plásticos y microplásticos presentes en la totalidad de las egagrópilas (pi=ni/N=1.1, Tabla 1), forman un sustrato ideal para el desarrollo de biopelículas con cepas de bacterias resistentes al pH gástrico de la especie y que, potencialmente, pueden afectarla (Tu et al. 2020, Wiemeyer et al. 2021). Dado que C. atratus posee un área de campeo cercana a los $35 \mathrm{~km}^{2}$ (Holland et al. 2017), las bacterias podrían ser dispersadas a otras áreas y, directa o indirectamente, afectar a otras especies y al propio ser humano (Plaza et al. 2019, 2020, Wiemeyer et al. 2021). De hecho, estudios recientes proponen que C. atratus, al 
obtener alimento en vertederos, podría ser un posible vector de bacterias del género Salmonella y Chlamydia (Plaza et al. 2019, 2020, Wiemeyer et al. 2021). Aunque el papel o rol epidemiológico de $C$. atratus aún no es claro (Plaza \& Lambertucci 2017, Plaza et al. 2020, Wiemeyer et al. 2021). En este sentido, distintos investigadores (Plaza et al. 2019; Wiemeyer et al. 2021), destacan la necesidad de una mayor atención del tema por parte de los administradores de salud pública. Asimismo, destacan la importancia de mejores políticas de gestión de residuos tendientes a una reducción de la exposición de la vida silvestre a los desechos orgánicos; evitando con ello la probabilidad de que estos animales actúen como portadores de patógenos.

En el presente estudio, el plástico aparece en todas las egagrópilas analizadas $(100 \%, \mathrm{pi}=\mathrm{ni} / \mathrm{N}=1.1$, Tabla 1 , Fig. 5). La ingesta de estos materiales puede tener efectos nocivos, no sólo debido a los efectos mecánicos y físicos en el tracto digestivo (Houston et al. 2007); sino también, a la toxicidad química que potencialmente presentan asociada a muchos de ellos; incluido el componente suelo (Hui \& Beyer 1998, Hui 2004). Algunas categorías de plástico contienen, entre otros tóxicos, ftalatos y bifenilos que se absorben fácilmente en el intestino y que podrían tener efectos teratogénicos y afectar negativamente las poblaciones de C. atratus (Iñigo 1987, Ballejo \& De Santis 2017). Otro tóxico, es el bisfenol A; un compuesto activo de propiedades estrogénicas considerado disruptor endócrino y que afecta, tanto al ser humano, como a un amplio abanico de especies (García et al. 2015, Sarria et al. 2019). Este compuesto se encuentra generalmente en los plásticos de categoría III (pi =ni/N=0.02) y 7 (pi=ni/ $\mathrm{N}=0.03$ ) (Tabla 1, Fig. 5), aunque puede estar en otras categorías también (Categoría VI, pi=ni/N=0.08). Tanto el bisfenol A, como los ftalatos, pueden hallarse incluso en los plásticos de categoría I (Bach et al. 2012) (pi=ni/ $\mathrm{N}=0.05$, Tabla 1, Fig. 5). Los ftalatos se encuentran preferentemente en los plásticos de categoría III; pero también, junto a otras toxinas, en los de categoría I (Bach et al. 2012) (Tabla 1, Fig. 5).

El PVC (categoría III) suele contener dioxinas, conocidas por sus efectos carcinógenos y teratogénicos entre otros (Cruz et al. 2010) (Tabla 1, Fig. 5). El poliestireno (pi=ni/N=0.08) (Categoría VI, Tabla 1, Fig. 5) contiene tóxicos como el estireno y el benceno. Ambas sustancias se consideran, al menos para seres humanos y animales de laboratorio, como cancerígenas, y pueden acarrear complicaciones de salud; incluyendo efectos perjudiciales sobre el sistema nervioso, respiratorio y reproductivo, y posiblemente en los riñones y el hígado (ONU 2018).

Por otro lado, los plásticos en general, también se constituyen en vectores de COP's tales como el DDT, DDE y HCH (Iñigo 1987, Teuten et al. 2009, Tu et al. 2020, Stothra Bhashyam et al. 2021). Mismos que prohíbe la constitución de Ecuador (2008). Empero, se los comercia libremente junto a otros biocidas y disruptores endócrinos como el glifosato, que también afecta a las aves silvestres (Gill et al. 2018). En el vertedero se halló envases plásticos de diferentes COP's y glifosato durante todo el período de estudio. Por tanto, existe el problema potencial de ingesta de tales biocidas a través de los plásticos y otros MA asociados a ellos. Sin embargo, como bien indican Plaza y Labertucci (2017), el impacto de este problema sobre la salud de los individuos y poblaciones de estas carroñeras está escasamente conocido. Incluso la presencia de grandes concentraciones de estas aves cerca de cuerpos de agua podría representar un riesgo de contaminación a través de sus heces (Plaza \& Lambertucci 2020).

Los microplásticos constituyen un problema a nivel global y, dado que la actual producción mundial de plásticos es exponencial, se espera lo propio con los microplásticos. Especialmente los microplásticos secundarios derivados de la fragmentación y erosión (Carlin et al. 2020, Stothra Bhashyam et al. 2021). La incidencia de microplásticos ha sido relativamente bien estudiada en aves acuáticas (Wilcox et al. 2015); pero es poco conocida en aves rapaces (Carlin et al. 2020). En este estudio, los microplásticos identificados en forma certera (Tabla 1, Fig. 5), en todos los casos, fueron microplásticos secundarios y, como los demás tipos de plásticos discutidos previamente, estos también afectan la salud de las aves a través de la ingestión principalmente (Wilcox et al. 2015, Carlin et al. 2020, Stothra Bhashyam et al. 2021). Los microplásticos tuvieron la mayor frecuencia en este estudio, donde se los halló en el $81 \%$ de las muestras ( $\mathrm{n}=90, \mathrm{pi}=\mathrm{ni} / \mathrm{N}=0.29$, Tabla 1$)$. Aunque, como se indicó previamente, este dato está subestimado; dado que no se consideró a las partículas inferiores a $1 \mathrm{~mm}$ y tampoco los fragmentos de fibras comprendidos en el tamaño estándar propuesto para los microplásticos (Carlin et al. 2020). Estudios recientes también han encontrado correlación entre microplásticos en plumas y materia fecal de diferentes especies de aves (Reynolds \& Ryan 2018).

Los plásticos y microplásticos aquí hallados en las egagrópilas de $C$. atratus, contribuyen y apoyan la predicción de Wilcox et al. (2015) quienes pronosticaron que para el año 2050, el 99\% de las aves a nivel global estaría afectado por plástico, ya sea por ingestión o por enredo (aves acuáticas especialmente). Complementariamente, Noreen y Sultan (2021), en su revisión global del tema confirman que la ingestión de material plástico incide en la tasa de mortalidad de las aves que lo consumen. De hecho, las poblaciones de cóndores y buitres a nivel global han disminuido drásticamente, entre otras, por esta causa (Houston et al. 2007, Noreen \& Sultan 2021). Finalmente, los microplásticos, por su relación superficie volumen, son vectores muy eficientes de compuestos orgánicos persistentes (COP's) (Teuten et al. 2009, Tu et al. 2020) que, como se mencionó, potencialmente pueden afectar la salud de estas especies. De acuerdo con sus propiedades físico-mecánicas como dureza, filo, rugosidad, algunos plásticos y otros MA ingeridos (vidrio, porcelana, metal) pueden causar daños mecánicos en distintas partes del tracto digestivo (Iñigo 1987) (Fig. 6) o pueden obstruirlo, sobre todo, si son ofrecidos a las crías (Houston et al. 2007, Walters et al. 2010, Plaza \& Lambertucci 2017). Al menos, para el caso de los buitres y cóndores, sus polluelos consumen más cantidad de MA que los adultos y, por 
dicha razón, se constituye en la principal causa de mortalidad para muchas especies; entre ellas, el cóndor de california (Gymnogyps californianus) (Houston et al. 2007). Una parte representativa de los materiales hallados en las egagrópilas cumplen con estas características (Figs. 4 y 6 , Tabla 1, Fig. 5), especialmente los metales, vidrio y otros (Incertae saedis, Tabla 1, Fig. 5).

Otro de los elementos hallados en las egagrópilas, fue la categoría "suelo". En este punto, es oportuno aclarar que el "polvo" como elemento similar (Categoría Incerta saedis) fue hallado en todas las egagrópilas ( $\mathrm{n}=112,100$ $\%)$ al desarmarlas. Al parecer como parte de la rotura y fragmentación de su propia estructura luego del proceso de secado. Dentro de la categoría "suelo" (Tabla 1, Fig. 5) sólo incluimos a elementos del suelo local $(n=9,8 \%$, pi = $\mathrm{ni} / \mathrm{N}=0.03$ ), donde la cantidad hallada era perceptiblemente evidente y, bajo la lupa (10x), mostró una estructura y composición física (granulometría, aspecto, color) idéntica al suelo del vertedero.

La geofagia es relativamente frecuente en aves (Hui 2004, Downs et al. 2019), pero es probable que el "suelo" encontrado en las muestras haya sido ingerido en un intento de tomar algún alimento sobre el mismo. La presencia de suelo es importante tomando en consideración que los vertederos son, con frecuencia, una fuente de metales pesados y otras toxinas, cuya bioacumulación y biomagnificación en aves que se alimentan en estos puede resultar letal (Hui 2004). Por tales motivos, diferentes autores (Hui 2004, Pollack et al. 2017, Plaza y Lambertucci 2017, Noreen \& Sultan 2021) señalan la necesidad urgente de más estudios sobre los efectos y consecuencias de metales pesados y toxinas orgánicas. Otros autores (Beyer et al. 1994, Hui 2004, Downs et al. 2019), destacan la importancia de cuantificar la cantidad de suelo ingerido, así como la eventual asociación de estos con otros MA por su importancia en procesos de bioacumulación y biomagnificación de compuestos tóxicos.

La sobreabundancia de una especie en particular, en este caso $C$. atratus, podría tener un impacto en la biodiversidad local (Plaza y Lambertucci 2017, Noreen \& Sul$\tan 2021$ ). Se ha visto (Plaza \& Lambertucci 2017) que las especies que se alimentan en vertederos tienen un tamaño y condición corporal mayor que incidiría en su aptitud (por ejemplo, mejorando sus habilidades competitivas). Por tanto, los vertederos de basura podrían jugar un papel como selector antropogénico de algunos genes, lo que puede producir consecuencias desconocidas en el ecosistema y niveles de población (Plaza \& Lambertucci 2017).

Actualmente se reconoce que los buitres en general (Accipitridae y Cathartidae) juegan uno de los más importantes roles ecológicos de la biodiversidad (Gangoso et al. 2013, Moleón et al. 2014, Noreen \& Sultan 2021), especialmente en servicios ambientales de las categorías de regulación, cultural y soporte. Determinando con ello una relación milenaria (al menos desde el Mioceno tardío, Moleón et al. 2014) de simbiosis mayormente mutualista; pero actualmente cuestionada frente a los problemas evidenciados en este artículo y en la literatura citada. Si bien no hay evidencia científica clara de que los buitres jueguen un papel epidemiológico en la propagación de microorganismos a los seres humanos y otras especies (Plaza \& Lambertucci 2018, Plaza et al. 2019, 2020, Wiemeyer et al. 2021); existe en cambio, información certera de que pueden prevenir la propagación de enfermedades infecciosas mediante la eliminación de la materia orgánica en descomposición, prestando un muy importante servicio ambiental que los humanos reciben sin costo alguno (Markandya et al. 2008, Moleón et al. 2014, Plaza et al. 2020). Los estudios realizados en diferentes partes del mundo muestran que estas especies anualmente quitan de los ecosistemas toneladas métricas de huesos, carne y residuos similares que, de permanecer en ellos, se convertirían en focos infecciosos con costos económicos que superan, en muchos casos, billones de dólares (Markandya et al. 2008, Moleón et al. 2014). De igual forma, existe evidencia de que las tasas de enfermedades infecciosas, tanto en humanos como en ganado, serían sustancialmente mayores en ausencia de buitres (Moleón et al. 2014).

Lo cierto es que, como indican Noreen y Sultan (2021), históricamente los vertederos de residuos jugaron un papel importante en el sostenimiento y florecimiento de poblaciones de especies carroñeras en torno a ellos. Pero, en tiempos más recientes el cambio en la composición de los residuos vertidos ha tenido un incremento exponencial de plásticos y otros MA como metales pesados, biocidas (organoclorados, organofosforados, piretroides) y medicamentos tóxicos (diclofenaco y otros) que se están convirtiendo en una sentencia de muerte para estas especies a nivel global (Ogada et al. 2012, Plaza et al. 2019, Noreen \& Sultan 2021).

Más allá de los vínculos e interrelaciones ecológicas de la especie con los ecosistemas antropogénicos, se debe considerar desarrollar líneas de investigación tendientes a estudiar los potenciales efectos vinculados a la ingesta de las diferentes categorías de plástico y demás materiales antropogénicos aquí documentadas. Todo ello permitirá desarrollar una línea base de conocimientos que permitan cuantificar en toda su magnitud los servicios ambientales que presta esta especie. Con ello se podrá diseñar políticas más adecuadas de manejo y conservación para la especie y vertederos de residuos. Así como políticas de integración armónica de C. atratus a los ecosistemas antropogénicos.

\section{Literatura citada}

Angeoletto F, Tryjanowski P, Fellowes M. (eds) 2022. Ecology of Tropical Cities: Natural and Social Sciences Applied to the Conservation of Urban Biodiversity. Springer, Cham. In Press.

Augé AA. 2017. Anthropogenic debris in the diet of turkey vultures (Cathartes aura) in a remote and low-populated South Atlantic island. Polar Biology 40, 799-805. https://doi.org/10.1007/s00300-016-2004-0

Bach C, Dauchy X, Chagnon M, Etienne S. 2012. Chemical compounds and toxicological assessments of drinking water stored in polyethylene terephthalate (PET) bottles: A source of controversy reviewed. Water Research 46 (3): 571-583. https://doi.org/10.1016/j. watres.2011.11.062. 
Ballejo F, De Santis LJM. 2013. Dieta estacional del jote cabeza negra (Coragyps atratus) en un área rural y una urbana. Hornero 28, 7-14. Disponible en https://bibliotecadigital.exactas.uba.ar/download/hornero/hornero_v028_n01_p007.pdf

Ballejo F, Plaza P, Speziale KL et al. 2020. Plastic ingestion and dispersion by vultures may produce plastic islands in natural areas. Science of the Total Environment (MS) https://doi.org/10.1016/j.scitotenv.2020.142421

Barnes DK, Galgani F, Thompson RC, Barlaz M. 2009. Accumulation and fragmentation of plastic debris in global environments. Philosophical Transactions of the Royal Society B: Biological Sciences 364, 1985-1998. https:// doi.org/10.1098/rstb.2008.0205

Beyer WN, Connor EE, Gerould S. 1994. Estimates of soil ingestion by wildlifeJournal of Wildlife Management 58:375-382. https://doi.org/10.2307/3809405

Carlin J, Craig C, Little S, Donnelly M, Fox D, Zhai L, Walters L. 2020. Microplastic accumulation in the gastrointestinal tracts in birds of prey in central Florida, USA. Environmental Pollution 2020 Sep; 264:114633. https:// doi.org/10.1016/j.envpol.2020.114633.

Chamberlain CP, Waldbauer JR, Fox-Dobbs K, Newsome SD, Koch PL, Smith DR, Church ME, Chamberlain SD, Sorenson KJ, Risebrough R. 2005. Pleistocene to recent dietary shifts in California condors. Proceedings of the National Academy of Sciences of the United States of America 102, 16707-16711. https://doi. org/10.1073/pnas.0508529102

Coleman JS, Fraser JD. 1987. Food habits of Black and Turkey vultures in Pennsylvania and Maryland. Journal of Wildlife Management 51: 733-739. https://doi. org/10.2307/3801734

Courtney A, Baker J, Bamford H. 2009. Proceedings of the International Research Workshop on the Occurrence, Effects and Fate of Microplastic Marine Debris. Sept 9-11, 2008. NOAA Technical Memorandum NOSOR\&R-30. 49 p. Disponible en https://marinedebris. noaa.gov/proceedings-international-research-workshop-microplastic-marine-debris

Cruz Carrillo A, Moreno Figueredo G, Lara Osorio M. 2010. Toxicología de las dioxinas y su impacto en la salud humana. Revista de Medicina Veterinaria (19): 73-84. https://doi.org/10.19052/mv.787

Downs CT, Bredin IP, Wragg PD. 2019. More than Eating Dirt: A Review of Avian Geophagy. African Zoology 54 (1): 1-19. https://doi.org/10.1080/15627020.2019.1570 $\underline{335}$

Fernández ÁL. 2020. La era del plástico. Editora Guadalmazán, Córdoba, España.

Flores-Tena FJ, Guerrero-Barrera AL, Avelar-González FJ, Ramírez-López EM, Martínez-Saldaña MC. 2007. Pathogenic and opportunistic Gram-negative bacteria in soil, leachate and air in San Nicolás landfill at Aguascalientes, Mexico. Revista Latinoamericana de Microbiologia. 49: 25-30.

Gangoso L, Agudo R, Anadon JD, de la Riva M, Suleyman AS, Porter R, Donazar JA. 2013. Reinventing mutualism between humans and wild fauna: insights from vultures as ecosystem services providers. Conservation Letters 6, 172e179. https://doi.org/10.1111/j.1755263X.2012.00289.X

García AJ, Gallego C, Font G. 2015. Toxicidad del Bisfenol A: Revisión. Revista de Toxicología (2015) 32: 144-160.
Geyer R, Jambeck JR, Lavender Law L. 2017. Production, use, and fate of all plastics ever made. Science Advances 3, e1700782. https://doi.org/10.1126/sciadv.1700782

Gill JPK, Sethi N, Mohan A et al. 2018. Glyphosate toxicity for animals. Environmental Chemistry Letters 16:401426. https://doi.org/10.1007/s10311-017-0689-0

Hiraldo F, Delibes M, Donazar JA. 1991. Comparison of Diets of Turkey Vultures in Three Regions of Northern Mexico. Journal of Field Ornithology 62 (3), 319-324. Disponible en https://www.jstor.org/stable/20065796

Holland AE, Byrne ME, Bryan AL, DeVault TL, Rhodes OE, Beasley JC. 2017. Fine-scale assessment of home ranges and activity patterns for resident black vultures (Coragyps atratus) and turkey vultures (Cathartes aura). PLoS One 12(7): e0179819. https://doi.org/10.1371/ journal.pone.0179819

Houston DC, Mee A, McGrady M. 2007. Why do condors and vultures eat junk? The implications for conservation. Journal of Raptor Research 41 (3): 235-238. https:// doi.org/10.3356/0892-1016(2007)41[235:WDCAVE 12.0. $\mathrm{CO} ; 2$

Houston DC. 1988. Competition for food between Neotropical vultures in forest. Ibis 130:402-417. https://doi. org/10.1111/j.1474-919X.1988.tb00998.x

Hui CA, Beyer WN. 1998. Sediment ingestion of two sympatric shorebird species. Sci Total Environ 224:227-233. https://doi.org/10.1016/S0048-9697(98)00361-1

Hui CA. 2004. Geophagy and Potential Contaminant Exposure for Terrestrial Vertebrates. In: Ware GW (eds) Reviews of Environmental Contamination and Toxicology, vol. 183. Springer, Nueva York, NY. https://doi. org/10.1007/978-1-4419-9100-3 5

INEN (Instituto Ecuatoriano de Normalización). 2012. Norma técnica ecuatoriana, NTE INEN 2634:2012. Disposición de desechos plásticos postconsumo. Requisitos. Primera Edición. NTE, Ecuador. 14 p. https:// www.ambiente.gob.ec/wp-content/uploads/downloads/2014/05/NTE-INENE-2634-Plasticos-postconsumo.pdf

Iñigo E. 1987. Feeding habits and ingestion of synthetic products in a Black Vulture population from Chiapas, Mexico. Acta Zoológica Mexicana 9:1-15. https://doi. org/10.21829/azm.1987.19222040

Johnston F. 2001. Synanthropic birds of North America. In: Marzluff JM, Bowman R, Donnelly R. (Eds.), Avian Ecology in an Urbanizing World. Kluwer Academic Publishers, Norwell, MA, pp. 49-67. https://doi. org/10.1007/978-1-4615-1531-9 3

Katyal DE, Kong E, Villanueva J. 2020. Microplastics in the environment: impact on human health and future mitigation strategies. Environmental Health Review. 63 (1): 27-31. https://doi.org/10.5864/d2020-005

Kelly NE, Sparks DW, DeVault TL, Rhodes OE. 2007. Diet of Black and Turkey Vultures in a Forested Landscape. Wilson Journal of Ornithology 119, 267-270. https:// doi.org/10.1676/05-095.1

Lambertucci SA, Trejo A, Di Martino S, Sánchez-Zapata JA, Donázar JA, Hiraldo F. 2009. Spatial and temporal patterns in the diet of the Andean condor: ecological replacement of native fauna by exotic species. Animal Conservation 12(4): 338-345. https://doi.org/10.1111/ j.1469-1795.2009.00258.x

Magurran AE. 1988. Ecological Diversity and Its Measurement. Princeton University Press. 
Margalida A, Sánchez-Zapata JA, Blanco G, Hiraldo F, Donázar JA. 2014. Diclofenac Approval as a Threat to Spanish Vultures. Conservation Biology. 28(3):631-632. https://doi.org/10.1111/cobi.12271.

Markandya A, Taylor T, Longo A, Murty MN, Murty S, Dhavala K. 2008. Counting the cost of vulture decline: An appraisal of the human health and other benefits of vultures in India. Ecological Economics 67: 194-204. https:// doi.org/10.1016/j.ecolecon.2008.04.020

Matejczyk M, Plaza GA, Nalęcz-Jawecki G, Ulfig K, MarkowskaSzczupak A. 2011. Estimation of the environmental risk posed by landfills using chemical, microbiological and ecotoxicological testing of leachates. Chemosphere 82(7):1017-1023. https://10.1016/j.chemosphere.2010.10.066

McKinney ML. 2002. Urbanization, biodiversity, and conservation. BioScience 52(10): 883 - 890. https://doi. org/10.1641/0006-3568(2002)052[0883:UBAC]2.0. $\mathrm{CO} ; 2$

Mee A, Rideout BA, Hamber JA, Todd JN, Austin G, Clark M, Wallace MP. 2007. Junk ingestion and nestling mortality in a reintroduced population of California Condors Gymnogyps californianus. Bird Conservation International 17:119-130. https://doi.org/10.1017/ S095927090700069X

Moleón M, Sánchez-Zapata J, Margalida A, Carrete M, OwenSmith N, Donázar J. 2014. Humans and Scavengers: The Evolution of Interactions and Ecosystem Services. BioScience 64(5): 394-403. http://www.jstor.org/stable/90006686

Noreen Z, Sultan K. 2021. A global modification in avifaunal behavior by use of waste disposal sites (waste dumps/ rubbish dumps): A review paper. Pure and Applied Biology (10)3: 603-616. http://dx.doi.org/10.19045/ bspab.2021.100062

Novaes WG, Cintra R. 2013. Factors influencing the selection of communal roost sites by the Black Vulture Coragyps atratus (Aves: Cathartidae) in an urban area in Central Amazon. Zoologia (Curitiba) 30(6):607-614. https:// dx.doi.org/10.1590/S1984-46702013005000014

Oaks JL, Meteyer CU. 2012. Nonsteroidal Anti-inflammatory Drugs in Raptors. Fowler's Zoo and Wild Animal Medicine 349-355. https://10.1016/b978-1-4377-1986$\underline{4.00046-9}$

Ogada DL, Keesing F, Virani MZ. 2012. Dropping dead: causes and consequences of vulture population declines worldwide. Annals of the New York Academy of Sciences 1249: 57-71. https://doi.org/10.1111/i.17496632.2011.06293.x

ONU Medio Ambiente. 2018. Plásticos de un solo uso: Una hoja de ruta para la sostenibilidad. 6ta Ed. 104 p. https:// www.unep.org/es/resources/informe/plasticos-deun-solo-uso-una-hoja-de-ruta-para-la-sostenibilidad

Oro D, Genovart M, Tavecchia G, Fowler MS, Martínez-Abraín A. 2013. Ecological and evolutionary implications of food subsidies from humans. Ecology Letters 16:1501e1514. https://doi.org/10.1111/ele.12187

Parfitt J, Barthel M, Macnaughton S. 2010. Food waste within food supply chains: quantification and potential for change to 2050. Philosophical Transactions of the Royal Society of London B: Biological Sciences 365(1554): 3065-3081 https://doi.org/10.1098/ rstb.2010.0126
Paterson RL. 1984. High incidence of plant material and small mammals in the autumn diet of Turkey Vultures in Virginia. Wilson Bulletin 396:467-469.

Plaza PI, Blanco G, Lambertucci SA. 2020, Implications of bacterial, viral and mycotic microorganisms in vultures for wildlife conservation, ecosystem services and public health. Ibis 162: 1109-1124. https://doi. org/10.1111/ibi.12865

Plaza PI, Blanco G, Madariaga MJ, Boeri E, Teijeiro ML, Bianco G, Lambertucci SA. 2019. Scavenger birds exploiting rubbish dumps: Pathogens at the gates. Transboundary and Emerging Diseases 66: 873- 881. https:// doi.org/10.1111/tbed.13097

Plaza PI, Lambertucci SA. 2017. How are garbage dumps impacting vertebrate demography, health, and conservation? Global Ecology and Conservation 12(2017): 9 - 20. https://doi.org/10.1016/i.gecco.2017.08.002

Plaza PI, Lambertucci SA. 2018. More massive but potentially less healthy: Black vultures feeding in rubbish dumps differed in clinical and biochemical parameters with wild feeding birds. PeerJ 6: e4645. https://doi. org/10.7717/peerj.4645

Pollack L, Ondrasek NR, Calisi R. 2017. Urban health and ecology: the promise of an avian biomonitoring tool. Current Zoology 63(2):205-212. https://doi.org/10.1093/cz/ zox011

Reynolds C, Ryan PG. 2018. Micro-plastic ingestion by waterbirds from contaminated wetlands in South Africa. Marine Pollution Bulletin 126:330e333. https://doi. org/10.1016/j.marpolbul.2017.11.021

Rideout BA, Stalis I, Papendick R, Pessier A, Puschner B, Finkelstein ME, Smith DR, Johnson M, Mace M, Stroud $\mathrm{R}$, et al. 2012. Patterns of mortality in free-ranging California Condors (Gymnogyps californianus). Journal of Wildlife Diseases 48:95-112 https://doi. org/10.7589/0090-3558-48.1.95

Sarria A, Gallo J, Pérez E. 2019. Bisphenol-A: A contaminant present in plastic containers. Revista ITTPA, 01 (01): 35-41. Disponible en: https://bit.ly/3thzYf3

Sazima I. 2007. From carrion-eaters to bathers' bags plunderers: how Black Vultures (Coragyps atratus) could have found that plastic bags may contain food. Revista Brasileira de Ornitologia 15:617-620. Disponible en https://bit.ly/35RX7K9

SEO/BirdLife (2018). Código Ético para la Observación de Aves. Sociedad Española de Ornitología. Madrid. https:// seo.org/wp-content/uploads/2018/09/Codigo_etico_aves_SEO_-2018.pdf

Steffen W, Sanderson A, Tyson PD, Jäger J, Matson PA, Moore III B, Oldfield F, Richardson K, Schellnhuber HJ, Turner BL, Wasson RJ. 2004. Global Change and the Earth System: A Planet Under Pressure. New York: SpringerVerlag Berlin Heidelberg.

Stothra Bhashyam S, Nash R, Deegan M, Pagter E, Frias J. 2020. Microplastics in the marine environment: sources, impacts and recommendations. Research@THEA [Reporte del Marine and Freshwater Research Centre at the Galway-Mayo Institute of Technology] http://research.thea.ie/handle/20.500.12065/3593.

Swan GE, Cuthbert R, Quevedo M, Green RE, Pain DJ, Bartels P, et al. 2006. Toxicity of diclofenac to Gyps vultures. Biology Letters:279-282. https://doi.org/10.1098/ $\underline{\text { rsbl.2005.0425 }}$ 
Tauler-Ametller H, Hernández-Matías A, Parés F, Pretus JL, Real J. 2018. Assessing the applicability of stable isotope analysis to determine the contribution of landfills to vultures' diet. PLoS ONE 13 (5): e0196044. https:// doi.org/10.1371/journal.pone.0196044

Teuten EL, Saquing JM, Knappe DR, Barlaz MA, Jonsson S, Björn A, Rowland SJ, Thompson RC, Galloway TS, Yamashita R, Ochi D, Watanuki Y, Moore C, Viet PH, Tana TS, Prudente M, Boonyatumanond R, Zakaria MP, Akkhavong K, Ogata Y, Takada H. 2009. Transport and release of chemicals from plastics to the environment and to wildlife. Philosophical transactions of the Royal Society of London. Series B, Biological sciences, 364 (1526), 2027-2045. https://doi.org/10.1098/rstb.2008.0284

Thomaides C, Valdez R, Reid WH, Raitt RJ. 1989. Food habits of turkey vultures in West Texas. Journal of Raptor Research 23:42-44.

Tu C, Zhou Q Zhang C, Liu Y, Luo Y. 2020. Biofilms of Microplastics. In: He D., Luo Y. (eds) Microplastics in Terrestrial Environments. The Handbook of Environmental Chemistry, 95. Springer, Cham. https://doi. org/10.1007/698 2020 461

Walters JR, Derrickson SR, Fry MD, Haig SM, Marzluff JM, Wunderle JM. 2010. Status of the California Condor (Gymnogyps californianus) and efforts to achieve its recovery. The Auk 127:969-1001. http://dx.doi. org/10.1525/auk.2010.127.4.969

Wiemeyer GM, Plaza PI, Bustos CP, Muñoz AJ, Lambertucci SA. 2021. Exposure to Anthropogenic Areas May Influence Colonization by Zoonotic Microorganisms in Scavenging Birds. International Journal of Environmental Research 18(10):5231. https://doi.org/10.3390/ijerph18105231

Wilcox C, Van Sebille E, Hardesty BD. 2015. Threat of plastic pollution to seabirds is global, pervasive, and increasing. Proceedings of the National Academy of Sciences of the United States of America 112, 11899e11904. https://doi.org/10.1073/pnas.1502108112

Witte R, Diesing D, Godde M. 1985. Urbanophobe, urbanoneutral, urbanophile - behavior of species concerning the urban habitat. Flora 177:265-282.

Yahner RH, Storm GL, Wrigth AL. 1990. Winter diets of vultures in Pennsylvania and Maryland. Wilson Bulletin 102:320-325. Disponible en http://www.jstor.org/stable/4162871

Zettler ER, Mincer TJ, Amaral-Zettler LA. 2013. Life in the 'plastisphere': microbial communities on plastic marine debris. Environmental Science \& Technology 47(13): 7137-7146. https://doi.org/10.1021/es401288x
Agradecimientos / Acknowledgments:

Los autores agradecen a los revisores anónimos y a los editores de la revista por las importantes y pertinentes sugerencias que contribuyeron notablemente a la versión final de este artículo.

Conflicto de intereses / Competing interests:

Los autores no incurren en conflictos de intereses.

\section{Rol de los autores / Authors Roles:}

ER: conceptualización, investigación, análisis formal, escriturapreparación del borrador original, redacción: revisión y edición. DICZ: investigación, análisis formal, escritura-preparación del borrador original, redacción: revisión y edición. FA: investigación, análisis formal, escritura-preparación del borrador original, redacción: revisión y edición. Todos los autores contribuyeron en la escritura, análisis de datos, revisión del manuscrito y dieron su aprobación a su versión final.

\section{Fuentes de financiamiento / Funding:}

Esta investigación no recibió ninguna subvención específica. El presente trabajo es un componente del Plan de acción: Investigación, docencia, extensión y formación de talento humano de la Carrera de Medicina de la Universidad San Gregorio de Portoviejo (Ecuador).

\section{Aspectos éticos / legales; Ethics / legals:}

Los autores declaran que el presente trabajo contó con la autorización oficial del Gobierno Municipal de Bolívar (Calceta) para el trabajo en el Vertedero Municipal de Residuos. Asimismo, el trabajo se contextualizó con el código de ética de observación y estudio de aves de SEO/Birdlife (2018). Para el trabajo de campo y de laboratorio se respetaron todos los protocolos de bioseguridad institucionales correspondientes (Universidad San Gregorio de Portoviejo) y del Instituto Nacional de Biodiversidad de Ecuador (INABIO). 